\title{
DETERMINATION OF HEAVY METALS IN WET DEPOSITION OF ATHENS
}

\section{E.A. KANELLOPOULOU}

Received: 26/06/00

Accepted: 23/02/01
Laboratory of Climatology

Department of Geology

University of Athens

15784 Athens, Greece

tel.: +30-1-7274192; fax: +30-1-7230963

\section{ABSTRACT}

The concentrations of ten industrial metals ( $\mathrm{Pb}, \mathrm{Cd}, \mathrm{Ni}, \mathrm{As}, \mathrm{Cr}, \mathrm{Zn}, \mathrm{Fe}, \mathrm{Cu}, \mathrm{Al}$ and $\mathrm{Mn}$ ) in 20 samples of rainwater collected at the station of Athens University Campus (AUC) during the cold period 1/10/97 31/3/98 were determined. In general, low concentrations were observed. The Spearman correlation coefficients for different metals were calculated in order to reveal common sources. Principal Component Analysis (PCA) was used to identify the factors that affect the presence of metals in rainwater.

KEY WORDS: Wet deposition, heavy metals, principal component analysis.

\section{INTRODUCTION}

The study of chemical composition of atmospheric aerosols is especially significant, because of the immediate influence on human health and ecosystems in general. The heavy metals that are emitted in the atmosphere in the form of aerosols, mainly from human activities, are taken away by wet or dry deposition and cause damages to the surface waters and the organisms living there. Also, the metals are absorbed by the plants through the rain, (Steinnea, 1990).

A great percentage of metals fall through the rain at the place of their production (Nurnberg et al., 1984). However, the aerosols, which have a very small falling velocity, are easily transferred by the wind and it is possible to be deposited through the rain at long distances from the point of their emission (Smirnioudi et al., 1998). Therefore, it is expected that chemical components in the rainwa- ter (acid components, anions, cations, and heavy metals) damage significantly the environment (surface waters, plants, animals, human beings). Dikaiakos et al. (1990) and Smirnioudi and Siskos (1992) have taken measurements about the acid components of rainwater in Athens while the presence of metals in specimens of wet and dry deposition in Athens, was studied for the first time by Smirnioudi et al. (1998).

In this study, the concentrations of 10 metals are determined ( $\mathrm{Pb}, \mathrm{Cd}, \mathrm{Ni}, \mathrm{Cr}, \mathrm{Al}, \mathrm{Cu}, \mathrm{Zn}, \mathrm{Mn}, \mathrm{Fe}$, As) during the cold period 1/10/97 - 31/3/98 at Ilissia station. Using Spearman method, the concentrations of metals were compared to each other as well as with the acidity and the conductivity of rainwater, in order that, significant correlation between them be revealed. In the process, the PCA method was applied on the metal concentrations. As it is well known the 
Table 1. Precipitation height, metal concentrations, $\mathrm{pH}$ and conductivity in wet deposition samples at Ilissia station of Athens University Campus during the cold period 1/10/97 - 31/3/98.

\begin{tabular}{|c|c|c|c|c|c|c|c|c|c|c|c|c|c|}
\hline Date & $\begin{array}{c}\text { Precipita- } \\
\text { tion } \\
\text { Height } \\
(\mathrm{cm})\end{array}$ & pH & \begin{tabular}{|c|} 
Con- \\
ductivity \\
$\left(\mu \mathrm{cm}^{-1}\right)$ \\
\end{tabular} & $\begin{array}{c}\mathbf{P b} \\
\left(\mu \mathrm{g} \mathrm{I}^{-1}\right)\end{array}$ & $\begin{array}{c}\mathbf{C d} \\
\left(\mu \mathrm{g} \mathbf{l}^{-1}\right)\end{array}$ & $\begin{array}{c}\mathbf{N i} \\
\left(\mu \mathrm{g} \mathrm{l}^{-1}\right)\end{array}$ & $\underset{\left(\mu \mathrm{g} \mathrm{l}^{-1}\right)}{\mathbf{A l}}$ & $\underset{\left(\mu \mathrm{g} \mathrm{l}^{-1}\right)}{\mathrm{Cr}}$ & $\begin{array}{c}\mathbf{Z n} \\
\left(\mu \mathrm{g} \mathrm{l}^{-1}\right)\end{array}$ & $\underset{\left(\mu \mathrm{g} \mathrm{I}^{-1}\right)}{\mathbf{C u}}$ & $\begin{array}{c}\mathrm{Mn} \\
\left(\mu \mathrm{g} \mathrm{I}^{-1}\right)\end{array}$ & $\begin{array}{c}\mathbf{F e} \\
\left(\mu \mathrm{g} \mathrm{l}^{-1}\right)\end{array}$ & $\begin{array}{c}\text { As } \\
\left(\mu g \mathrm{I}^{-1}\right)\end{array}$ \\
\hline 19/10/1997 & 0,10 & 6,75 & 72,00 & 0,75 & 0,35 & 3,10 & 3,57 & 1,05 & 31,0 & 19,0 & 5,90 & 6,49 & 2,3 \\
\hline 24/10/1997 & 0,10 & 6,60 & 36,40 & 0,28 & 0,18 & 7,24 & 27,8 & 1,25 & 115 & 21,2 & 3,48 & 2,82 & 1,2 \\
\hline 25/10/1997 & 2,70 & 5,90 & 11,70 & 1,45 & 0,20 & 3,29 & 6,52 & 0,52 & 33,2 & 12,8 & 1,77 & 9,21 & 1,6 \\
\hline 9/11/1997 & 0,70 & 7,50 & 70,40 & 0,14 & 0,12 & 6,91 & 0,24 & 1,58 & 15,4 & 7,52 & 1,87 & 1,41 & 0,00 \\
\hline 15/11/1997 & 0,00 & 7,01 & 70,00 & 3,67 & 0,54 & 15,1 & 32,0 & 4,47 & 155 & 63,7 & 14,2 & 10,2 & 1,8 \\
\hline 17/11/1997 & 1,40 & 5,86 & 20,80 & 3,47 & 0,24 & 4,60 & 5,80 & 1,84 & 38,2 & 16,8 & 2,86 & 9,30 & $1-2$ \\
\hline 24/11/1997 & 7,20 & 5,90 & 27,40 & 0,81 & 0,15 & 2,63 & 1,34 & 0,56 & 17,5 & 8,85 & 1,72 & 4,32 & 0,00 \\
\hline 25/11/1997 & 1,12 & 6,04 & 20,71 & 0,48 & 0,10 & 2,96 & 0,00 & 0,52 & 3,90 & 4,42 & 4,68 & 2,44 & 0,00 \\
\hline 1/12/1997 & 4,71 & 6,02 & 13,60 & 0,38 & 0,05 & 1,97 & 0,00 & 1,38 & 12,7 & $5-31$ & 1,61 & 4,23 & 0,00 \\
\hline 8/12/1997 & 2,39 & 7,02 & 116,2 & 0,00 & 0,29 & 2,96 & 6,23 & 2,11 & 29,3 & 11,5 & 1,61 & 2,16 & 0,00 \\
\hline $15 / 12 / 1997$ & 11,43 & 7,07 & 46,80 & 0,00 & 0,25 & 2,63 & 0,00 & 1,10 & 17,5 & 10,2 & 1,46 & 3,86 & 0,00 \\
\hline 27/12/1997 & 2,83 & 6,58 & 88,90 & 0,40 & 0,26 & 5,59 & 1,14 & 1,05 & 16,8 & 8,85 & 4,73 & 4,51 & 0,00 \\
\hline $12 / 1 / 1998$ & 0,10 & 6,63 & 126,0 & 1,12 & 0,51 & 13,8 & 5,36 & 2,63 & 47,1 & 31,0 & 12,9 & 2,44 & 1,0 \\
\hline $22 / 1 / 1998$ & 0,83 & 5,51 & 52,30 & 0,40 & 0,09 & 0,99 & 3,06 & 0,79 & 80,0 & 39,8 & 1,30 & 3,20 & 1,4 \\
\hline $23 / 1 / 1998$ & 2,48 & 5,43 & 10,10 & 0,87 & 0,03 & 1,32 & 2,93 & 0,26 & 4,64 & 8,85 & 1,61 & 3,10 & 1,0 \\
\hline 1/2/1998 & 1,78 & 6,00 & 25,70 & 1,30 & 0,10 & 1,32 & 1,24 & 0,79 & 7,86 & 8,41 & 3,59 & 3,01 & 1,1 \\
\hline 4/2/1998 & 0,96 & 7,50 & 61,20 & 0,34 & 0,14 & 1,32 & 10,04 & 0,26 & 2,86 & 7,52 & 0,73 & 1,88 & 1,7 \\
\hline $6 / 2 / 1998$ & 1,46 & 6,49 & 18,47 & 0,00 & 0,02 & 1,00 & 1,89 & 0,82 & 3,57 & 3.98 & 1,87 & 3,66 & 0,00 \\
\hline 11/3/1998 & 3,79 & 7,06 & 51,60 & 0,00 & 0,08 & 1,74 & 5,05 & 1,44 & 16,5 & 8,84 & 1,02 & 3,95 & 1,5 \\
\hline 16/3/1998 & 0,07 & 6,33 & 33,80 & 1.74 & 0,23 & 2.30 & 3,11 & 1,32 & 21,2 & 9,73 & 3,33 & 5,45 & 1,0 \\
\hline Mean & 2,31 & 6,46 & 48,70 & 0,88 & 0,20 & 4,14 & 5,87 & 1,29 & 33,46 & 15,41 & 3,61 & 4,38 & 0,84 \\
\hline S.D. & 2,81 & 0,62 & 33,81 & 1,05 & 0,14 & 3,97 & 8,67 & 0,97 & 40,81 & 14,51 & 3,68 & 2,54 & 0,77 \\
\hline Min & 0,00 & 5,43 & 10,10 & 0,00 & 0,02 & 0,99 & 0,00 & 0,26 & 2,86 & 3,98 & 0,73 & 1,41 & 0,00 \\
\hline Max & 11,43 & 7,50 & 126,00 & 3,67 & 0,54 & 15,10 & 32,00 & 4,47 & 155,00 & 63,70 & 14,20 & 10,20 & 2,30 \\
\hline Median & 1,43 & 6,54 & 41,60 & 0,44 & 0,16 & 2,80 & 3,08 & 1,08 & 17,50 & 9,29 & 1,87 & 3,76 & 1,00 \\
\hline
\end{tabular}

basic principle of PCA method is to group two or more variables by a single factor, which is linear combination of the variables. The explanation of these factors instead of the original variables gives us the possible common sources of the metals examined.

\section{SAMPLING AND ANALYSIS}

Description about the type of sampler used and the $\mathrm{pH}$ and conductivity determination meth- ods are given in a previous work (Kanellopoulou et al., 1998). The determinations of metals became through Atom Absorption Spectrometry with electrowiring graphite (Perkin-Elmer 5100PC) with THGA graphite oven and the correction of the reference level through the help of Zeeman phenomenon (Perkin-Elmer 5100ZL). The correctness of the results was checked by the use of reference specimen SLEW-2 (Riverine water). 

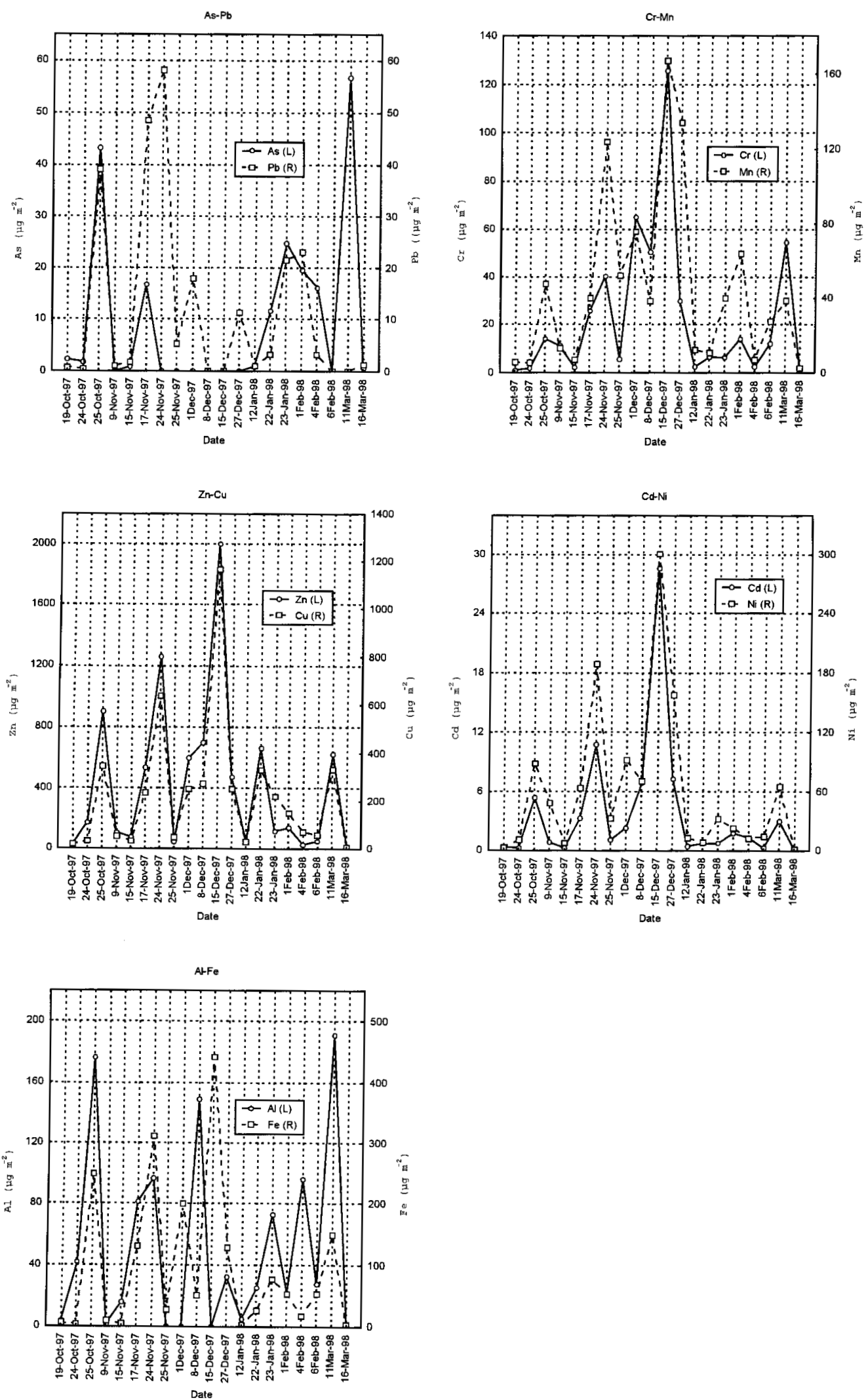

Figure 1. Fluctuation of superficial metal concentration in wet deposition samples during the cold period $1 / 10 / 97-31 / 3 / 98$. 
Table 2. Spearman correlation coefficients between the superficial metal concentration and the physicochemical parameters of wet deposition samples.

\begin{tabular}{|c|c|c|c|c|c|c|c|c|c|c|c|}
\hline & {$\left[\mathbf{H}^{+}\right]$} & Conductivity & $\mathbf{P b}$ & $\mathbf{C d}$ & $\mathbf{N i}$ & $\mathbf{A l}$ & $\mathbf{C r}$ & $\mathbf{Z n}$ & $\mathbf{C u}$ & $\mathbf{M n}$ & $\mathbf{F e}$ \\
\hline Conductivity & $-\mathbf{0 , 6 6}$ & - & & & & & & & & & \\
\hline $\mathbf{P b}$ & $\mathbf{0 , 7 4}$ & $-\mathbf{0 , 4 8}$ & - & & & & & & & & \\
\hline $\mathbf{C d}$ & 0,02 & $-0,04$ & 0,28 & - & & & & & & & \\
\hline $\mathbf{N i}$ & 0,04 & $-0,19$ & 0,22 & $\mathbf{0 , 9 1}$ & - & & & & & & \\
\hline $\mathbf{A l}$ & 0,13 & $-0,04$ & 0,14 & 0,31 & 0,19 & - & & & & & \\
\hline $\mathbf{C r}$ & 0,04 & $-0,16$ & 0,08 & $\mathbf{0 , 8 5}$ & $\mathbf{0 , 9 0}$ & 0,20 & - & & & & \\
\hline $\mathbf{Z n}$ & 0,21 & $-0,14$ & 0,15 & $\mathbf{0 , 7 4}$ & $\mathbf{0 , 7 4}$ & 0,37 & $\mathbf{0 , 8 0}$ & - & & & \\
\hline $\mathbf{C u}$ & 0,19 & $-0,21$ & 0,22 & $\mathbf{0 , 8 5}$ & $\mathbf{0 , 8 0}$ & 0,44 & $\mathbf{0 , 8 5}$ & $\mathbf{0 , 9 0}$ & - & & \\
\hline $\mathbf{M n}$ & 0,27 & $-0,34$ & 0,41 & $\mathbf{0 , 8 2}$ & $\mathbf{0 , 8 9}$ & $-0,00$ & $\mathbf{0 , 8 2}$ & $\mathbf{0 , 6 2}$ & $\mathbf{0 , 7 7}$ & - & \\
\hline $\mathbf{F e}$ & 0,29 & $\mathbf{- 0 , 4 9}$ & 0,35 & $\mathbf{0 , 8 3}$ & $\mathbf{0 , 8 6}$ & 0,27 & $\mathbf{0 , 8 6}$ & $\mathbf{0 , 5 8}$ & $\mathbf{0 , 8 8}$ & $\mathbf{0 , 8 6}$ & - \\
\hline $\mathbf{A s}$ & 0,26 & $-0,20$ & 0,24 & $-0,13$ & $-0,30$ & $\mathbf{0 , 5 0}$ & $-0,21$ & $-0,02$ & 0,03 & $-0,24$ & $-0,00$ \\
\hline
\end{tabular}

\section{RESULTS AND DISCUSSION}

The precipitation height, the metal concentrations, $\mathrm{pH}$ and conductivity in the wet deposition samples at Ilissia station of ALJC during the cold period 1/10/97 - 31/3/98 are given in Table 1 .

The superficial metal concentrations $\left(\mu \mathrm{g} \mathrm{m}^{-2}\right)$ are estimated by multiplying the precipitation height times the $\mathrm{m} / \mathrm{v}$ concentration $\left(\mu \mathrm{g} \mathrm{l}^{-1}\right)$. We remark that these concentrations are relatively low, with the exception of $\mathrm{Zn}$ concentration, on the contrary with a previous work by Smirnioudi et al. (1998).

The fluctuations of these concentrations in the rainwater samples during the studying period are given in Fig 1. It is remarkable that the min concentration values are dispersed during 1998, a fact that is under study and is possible to be associated with the wind blow. The max concentration values appeared in 19/11/1997, a day with trace of rain, because of the fact that there is a large amount of pollutants soluble in less solvent.

Applying the Kolmogorov-Smirnov test, it is proved that the conductivity and the concentrations of each metal follow logarithmic-normal distribution, while $\mathrm{pH}$ follows normal distribution. Since the examined results do not come from normal populations, the searching for the correlation between the metals and the physicochemical parameters is done using Spearman method. The Spearman correlation coefficients are given in
Table 2. Statistically significant correlations at 95\% significant level are shown in bold italics.

Strong correlation is observed among the industrial metals (Cd, Ni, Cr, Zn, Cu, Mn, Fe). Besides, Al, a metal coming from natural source, (is mainly associated with the natural composition of the earth's crust and be introduced to the atmosphere by soil erosion) is not correlated to the rest of the metals, but only to As, a metal which possibly comes from the mines of Lavrio with the southern wind blow. It is well known that huge heaps of black metal dust, which is used for sand blown technique, exists at the greater area of Lavrio, (Stavraki, 1998). The $\mathrm{Pb}$ is not correlated to the rest of the metals, while it is the only one metal, which is positively correlated to the $\left[\mathrm{H}^{+}\right]$concentration. The negative correlation between conductivity and $\left[\mathrm{H}^{+}\right]$shows that the alkalinity of rainwater is due to the increased concentration of the main cations $\left(\mathrm{H}^{+}, \mathrm{NH}_{4}^{+}, \mathrm{Na}^{+}, \mathrm{K}^{+}, \mathrm{Ca}^{2+}, \mathrm{Mg}^{2+}\right)$, which come from the sea or from the soil constituents, as also proposed by Smirnioudi et al. (1998). A better explanation will be given when the cations and anions will be determined to the corresponding samples, a project which is in progress. The metals $\mathrm{Cd}, \mathrm{Ni}, \mathrm{Cr}, \mathrm{Zn}, \mathrm{Cu}, \mathrm{Mn}, \mathrm{Fe}$, probably come from the same sources, (the industrial area of Thriasio basin, which is extended at the west of Athens or the National Highway and the factories 
Table 3. Coefficients of the first two principal components, after rectangular rotation.

\begin{tabular}{|c|c|c|}
\hline Metals & PC1 & PC2 \\
\hline $\mathbf{P b}$ & 0,27 & 0,54 \\
\hline $\mathbf{C d}$ & $\mathbf{0 , 9 6}$ & $-0,04$ \\
\hline $\mathbf{N i}$ & $\mathbf{0 , 9 8}$ & 0,04 \\
\hline $\mathbf{A l}$ & 0,05 & $\mathbf{0 , 9 1}$ \\
\hline $\mathbf{C r}$ & $\mathbf{0 , 9 0}$ & 0,03 \\
\hline $\mathbf{Z n}$ & $\mathbf{0 , 9 4}$ & 0,22 \\
\hline $\mathbf{C u}$ & $\mathbf{0 , 9 6}$ & 0,16 \\
\hline $\mathbf{M n}$ & $\mathbf{0 , 9 1}$ & $-0,01$ \\
\hline $\mathbf{F e}$ & $\mathbf{0 , 9 3}$ & 0,28 \\
\hline $\mathbf{A s}$ & $-0,10$ & $\mathbf{0 , 8 9}$ \\
\hline
\end{tabular}

at the north and north-east of Athens), which can be defined, only when the metal concentrations will be correlated to the wind directions.

The $\mathrm{Pb}$ seems to have separate source and obviously is the traffic circulation around the University campus. The $\mathrm{Pb}$ concentration is much lower than the concentration, which had been detected during the period from November 1989 to May 1991, (Smirnioudi et al., 1998). It is obvious that this is due to catalytic technology of the vehicles. We have to pinpoint that metals such as $\mathrm{Cd}, \mathrm{Cr}, \mathrm{Ni}$ and $\mathrm{Pb}$ exist in aerosols, in nimble form, soluble in water and are dispersed in the environment. Exactly the opposite happens with As and $\mathrm{Al}$ (Hlavay et al., 1998).

The previous results are confirmed by the application of PCA in the superficial metals concentrations. According to that analysis the $83 \%$ of the total variance is explained by two factors. The first factor (PC1) explains $64 \%$ of the total variance and represent the industrial metals $(\mathrm{Cd}, \mathrm{Ni}, \mathrm{Cr}, \mathrm{Zn}, \mathrm{Cu}$, $\mathrm{Mn}, \mathrm{Fe})$, which are emitted by anthropogenic activities while the second one (PC2) explains 19\% of the total variance and refers to $\mathrm{Al}$ and $\mathrm{As}$ as a group, which are mainly associated with natural sources (soil erosion and mines of Lavrio). After rectangular rotation (varimax) of the axes, the loadings of the two factors are given in Table 3.

The bold italic figures in Table 3 , in each one principal component (factor) declare the high correlation of the metals to the appropriate factor affecting them as a group.

\section{CONCLUSIONS}

The concentrations of heavy metals $(\mathrm{Pb}, \mathrm{Cd}, \mathrm{Ni}$, $\mathrm{As}, \mathrm{Cr}, \mathrm{Cu}, \mathrm{Zn}, \mathrm{Fe}, \mathrm{Al}$ and $\mathrm{Mn}$ ), which were determined in 20 samples of rainwater at Ilissia station of AUC, during the period 1/10/97 $31 / 3 / 98$ (cold period of the year), were relatively low with the exception of the $\mathrm{Zn}$. Using Spearman correlation method and the technique of Principal Component Analysis, it is found that the metals $\mathrm{Cd}, \mathrm{Ni}, \mathrm{Cr}, \mathrm{Zn}, \mathrm{Cu}, \mathrm{Mn}$ and $\mathrm{Fe}$ have common sources (the industrial area of Thriasio basin at the west of Athens or the National Highway and the factories at the north and northeast of Athens). The sources of $\mathrm{Pb}$ must be near the station (the traffic circulation around the University campus), while, $\mathrm{Al}$ and As seem to have their own common sources. The possible origin of $\mathrm{Al}$ is the soil erosion and the mines of Lavrio, at the greater vicinity of Athens, are the possible source of As.

\section{ACKNOWLEDGEMENTS}

Many thanks to Dr. N. Thomaidis, who determine the concentrations of the heavy metals in rainwater samples. 


\section{REFERENCES}

Dikaiakos, J.G., Tsitouris, C.G, Siskos, P.A., Melissos, D.A. and Nastos, P.Th. (1990), Rainwater composition in Athens, Greece, Aim. Env. 24 B, 171.

Hlavay, J., Polyak, K., Molnar, A. and Meszaros, E. (1998), Determination of the distribution of elements as a function of particle size in aerosol samples by sequential leaching, Analyst, 123, 859.

Kanellopoulou, E., Nastos, P., Pagonis, C. and Siskos, P. (1998), Conductivity and pH of rainwater during cold period in Athens, In: Proceedings of the $4^{\text {th }}$ Hellenic Congress in Meteorology-Climatology and Atmosphere Physics, Athens 22-25/9/98, 3, 397 (in Greek).

Nurnberg, H.W., Valenta, P., Nguyen, V.D., Godde, M. and Urano de Carralho, E. (1984), Studies on the deposition of acid and ecotoxic heavy metals with precipates from the atmosphere, Fresenius J. Anal. Chem., $317,314$.

Smirnioudi, V.N. and Siskos, P.A. (1992), The chemical composition of wet and dust deposition in Athens, Greece, Atm. Env. 26B, 845.

Smirnioudi, V., Thomaidis, M.S., Piperaki, E.A. and Siskos, P.A. (1998), Determination of trace metals in wet and dust deposition in Greece, Fres. Environ. Bul. 7, 85-90.

Stavraki-Xatzigeorgiou, P. (1998), Effects of heavy metals pollution at areas with mining activity to the health of local people, Ph.D. Thesis, University of Athens, Athens, 12-17.

Steinnea, E. (1990), Lead, Cadmium and other metals in Scandinavian surface waters, with emphasis on acidification and atmospheric deposition, Envir. Toxicol. Chem. 9, 825. 